\title{
TEMPORALIDADE, MUNDANIDADE E HISTORICIDADE: CONCEITOS FUNDANTES DOS SENTIDOS DE ENFERMEIRAS-DOCENTES ACERCA DA SAÚDE MENTAL
}

\author{
TEMPORALITY, WORLDLINESS AND HISTORICITY: \\ BASE CONCEPTS OF THE MEANINGS OF \\ NURSES-PROFESSORS ABOUT MENTAL HEALTH
}

\section{TEMPORALIDAD, MUNDANIDAD E HISTORICIDAD: CONCEPTOS FUNDAMENTALES DE LOS SIGNIFICADOS DE LAS ENFERMERAS-PROFESORES SOBRE LA SALUD MENTAL}

\author{
Aline Macedo de Queiroz ${ }^{1}$ \\ Josicélia Dumêt Fernandes ${ }^{2}$ \\ Larissa Chaves Pedreira ${ }^{3}$ \\ Elizabeth Teixeira ${ }^{4}$ \\ Andrey Ferreira da Silva ${ }^{5}$ \\ Lília Pereira Lima ${ }^{6}$ \\ Rita do Socorro Ribeiro Quaresma Oliveira ${ }^{7}$
}

Como citar este artigo: Queiroz AM, Fernandes JD, Pedreira LC, Teixeira E, Silva AF, Lima LP, et al. Temporalidade, mundanidade e historicidade: conceitos fundantes dos sentidos de enfermeiras-docentes acerca da saúde mental. Rev baiana enferm. 2020;34:e36930.

Objetivo: compreender os sentidos que fundam o modo de ser de enfermeiras-docentes em relação à saúde mental e como a saúde mental emerge em seu cotidiano de ser docente. Método: estudo fenomenológico. Utilizou-se entrevista fenomenológica com oito enfermeiras-docentes. Na análise, unidades de significação emergiram do sentido velado das falas: Compreende a saúde mental, na maioria das vezes, de modo impróprio como doença mental presente no falatório do cotidiano familiar e nos processos de sua formação acadêmica; Conceitos e pré-conceitos estabelecidos no processo de formação influenciados pelo modo de ser das docentes. Resultados: enfermeiras-docentes compreenderam a saúde mental de modo impróprio como doença e revelaram conceitos e preconceitos estabelecidos no seu cotidiano de ser docente. Conclusão: os sentidos fundantes do modo de ser das enfermeiras-docentes em relação à saúde mental estão ligados à temporalidade, mundanidade e historicidade, subordinados tanto ao falatório do cotidiano familiar como aos processos de sua formação acadêmica.

Descritores: Enfermagem. Saúde Mental. Ensino. Docentes de Enfermagem. Filosofia.

\footnotetext{
Enfermeira. Professora Adjunta da Universidade Federal do Pará. Belém, Pará, Brasil. alinemacedo@ufpa.br. https://orcid.org/0000-0002-7374-0I IX.

Enfermeira. Professora Emérita e Titular da Escola de Enfermagem da Universidade Federal da Bahia. Salvador, Bahia, Brasil. https://orcid.org/0000-0003-2946$53 \mid 4$.

Enfermeira. Professora Associada da Escola de Enfermagem da Universidade Federal da Bahia. Salvador, Bahia, Brasil. https://orcid.org/0000-000 I-8939-324X.

Enfermeira. Professora Titular aposentada da Universidade do Estado do Pará. Professora Visitante da Universidade do Estado do Amazonas. Manaus, Amazonas, Brasil. https://orcid.org/0000-0002-540 I-8I05.

Enfermeiro. Doutor em Enfermagem e Saúde. Professor Substituto da Universidade Federal de Alagoas. Maceió, Alagoas, Brasil. https://orcid.org/0000-0002- I0387443.

Enfermeira. Pesquisadora Independente. Salvador, Bahia, Brasil. https://orcid.org/0000-0002-4I 08-9705.

Enfermeira. Professora substituta da Universidade Federal do Pará. Belém, Pará, Brasil. https://orcid.org/0000-0002-7397-6448.
} 
Objective: to understand the meanings that underpin the way of being of nurses-professors in relation to mental health and how mental health emerges in their daily life of as a professor. Method: phenomenological study. A phenomenological interview was used with eight nurses-professors. In the analysis, meaning units emerged from the veiled sense of the statements: Understanding mental health often inappropriately as a mental illness present in the talk of family daily life and in the processes of their academic training; Concepts and pre-concepts established in the training process influenced by the professors' way of being. Results: nurses-professors understood mental bealth inappropriately as a disease and revealed concepts and prejudices established in their daily life as a professor. Conclusion: the base meanings of the nurses-professors' way of being in relation to mental bealth are linked to temporality, worldliness and historicity, subordinated to both the family daily discourse and to the processes of their academic training.

\section{Descriptors: Nursing. Mental Health. Teaching. Nursing Professors. Philosophy.}

Objetivo: entender los significados que fundamentan la forma de ser de enfermeras-profesoras en relación con la salud mental y cómo la salud mental emerge en su vida diaria de profesoras. Método: estudio fenomenológico. Se utilizó una entrevista fenomenológica con ocho enfermeras docentes. En el análisis, las unidades de significado surgieron del sentido velado de las declaraciones: Entiende la salud mental, en la mayoría de los casos, inapropiadamente como una enfermedad mental presente en el discurso de la vida cotidiana familiary en los procesos de su formación académica; Conceptos y pre-conceptos establecidos en el proceso de formación influenciados por la forma de ser de las profesoras. Resultados: las enfermeras-profesoras entendieron la salud mental inapropiadamente como una enfermedad y revelaron conceptos y prejuicios establecidos en su vida diaria como profesoras. Conclusión: los significados fundacionales de la forma de ser de las enfermeras docentes en relación con la salud mental están vinculados a la temporalidad, la mundanidad y la bistoricidad, subordinados tanto al discurso de la vida cotidiana familiar como a los procesos de su formación académica.

Descriptores: Enfermería. Salud Mental. Enseñanza. Profesores de Enfermería. Filosofía.

\section{Introdução}

A Atenção em Saúde Mental é campo de conhecimento que deve ser compreendido nas dimensões da transversalidade, especificidade e especialidade ${ }^{(1-2)}$. Estas defendem aspectos determinados, bem como explicitam que seus conteúdos estão contidos em todos os níveis de atenção à saúde, considerando o cuidado integral. Por isso, há necessidade de sua compreensão por aqueles que formam os profissionais para atuação no campo da saúde ${ }^{(3)}$. No processo de formação em saúde mental, pode-se considerar uma dessas dimensões para constituição dos conteúdos a serem ensinados, que revela os sentidos em que se ancora o plano de ensino. Assim, os modos de ser, pensar e fazer das enfermeiras-docentes em relação aos conteúdos e às dimensões da atenção à saúde mental constituem-se com base nos sentidos dados às experiências vividas em suas relações com os outros, refletindo o cuidado em saúde ${ }^{(4-6)}$.

$\mathrm{Na}$ perspectiva existencial, o cuidado em saúde, uma das formas de preservação da vida, está implícito nas relações da existência do ser e pode ser entendido como ato ou sentido quando se preocupa com o outro ${ }^{(6-7)}$. O sentido de cuidado trazido por Heidegger ${ }^{(8)}$ indica as possibilidades do ser no mundo, transformando-se na temporalidade como cura, favorecendo a permanência em vida. Nesse sentido, as pessoas estão no mundo em sua mundanidade, vivenciando situações cotidianas que interferem em seu estado emocional e em suas vivências, conduzindo-se a uma nova possibilidade de ser. Dessa forma, é importante que a dimensão da transversalidade seja apresentada no processo de formação dos profissionais de saúde e incorporada na Atenção Básica (AB), visto que atuam no cuidado em saúde para garantir atendimento integral à pessoa, principalmente no contexto da saúde mental ${ }^{(9)}$.

As Diretrizes Gerais para Inclusão das Ações de Saúde Mental na Atenção Básica afirmam que o vínculo e o diálogo entre a Política de Atenção Básica (PNAB) e a Política de Atenção em Saúde Mental (PNASM) são fundamentais para a garantia dos direitos da pessoa em sofrimento 
mental ${ }^{(2,10)}$. Preconizam, ainda, a existência de um componente subjetivo associado a toda e qualquer doença, na tentativa de perceber os entraves à adesão a práticas preventivas ou de vida mais saudáveis ${ }^{(3,10)}$. Compreender a subjetividade do sofrimento psíquico presente em qualquer problema é poder ampliar o conceito de saúde e as possibilidades de cuidado.

O exercício permanente na construção de novas formas de acolher e cuidar das pessoas que padecem mentalmente requer das instituições formadoras a constituição de sentidos junto aos docentes que atuam no campo da atenção integral e psicossocial ${ }^{(4,11)}$. Contudo, o cotidiano das práticas nos cenários de ensino/aprendizagem em saúde/enfermagem evidencia uma distância entre a PNASM e a PNAB, estabelecendo um descompasso na atenção à saúde integral da pessoa ${ }^{(4,12)}$. Esse descompasso relatado na literatura é observado na prática, principalmente de docentes vinculadas à $\mathrm{AB}, \mathrm{e}$ repercute no processo de formação, que não valoriza os preceitos para o cuidado integral em saúde mental.

Os modos de ser constroem-se ao longo do tempo, com base em vivências e trocas mundanas, onde o Ser-aí é capaz de fazer escolhas e projetar-se no mundo ${ }^{(12)}$. Nesse sentido, a forma que a(o) enfermeira(o) presta o cuidado pode revelar os modos de ser desses profissionais, principalmente daqueles que escolhem a docência como exercício profissional ${ }^{(7)}$.

No processo de formação da enfermeira, a atitude compreensiva constitui-se na relação, na confiança estabelecida entre docente, discentes e usuários do serviço, em suas vivências práticas $^{(7,13)}$. Ademais, se os conteúdos de atenção à saúde mental, nos currículos acadêmicos, são abordados de forma dicotomizada e transversal, a reprodução na prática também poderá continuar sem mudanças significativas no que se refere ao cuidado. Tal contexto foi confirmado em estudo $^{(13)}$ realizado com enfermeiras-docentes, ao desvelar que a atenção à saúde mental não se apresenta como conteúdo transversal na formação, não sendo uma ocupação antecipada em seus modos de ser enquanto docentes.
Diante desse contexto, questiona-se: Quais os sentidos que fundam o modo de ser de enfermeiras-docentes em relação à saúde mental e como a saúde mental emerge em seu cotidiano de ser docente? Assim, o objetivo do estudo é compreender os sentidos que fundam o modo de ser de enfermeiras-docentes em relação à saúde mental e como a saúde mental emerge em seu cotidiano de ser docente.

\section{Método}

Trata-se de um estudo fenomenológico, à luz do referencial de Martin Heidegger - a "hermenêutica do Ser-aí" -, proposta em seu livro "Ser e Tempo", no qual o autor ocupou-se de recolocar a questão do "sentido do ser" e buscou a construção de conhecimentos numa filosofia com foco na compreensão da experiência vivida pelo Ser-aí, entendido como o ente que possui, em seu modo de ser, entre outras coisas, a possibilidade de questionar-se e de buscar o sentido de ser sendo no mundo ${ }^{(8,14)}$.

O cenário de estudo foi a Faculdade de Enfermagem de uma instituição pública de ensino superior da região Norte do país, ambiente em que ocorrem as experiências cotidianas das enfermeiras-docentes no processo de formação em enfermagem. Participaram oito enfermeiras-docentes que atenderam aos critérios de inclusão: ser enfermeira, compor o quadro permanente de docentes, exercer a docência em atividade curricular (AC) que antecede à AC Enfermagem em Saúde Mental e Psiquiátrica, que contém conteúdo da $\mathrm{AB}$ e foram identificadas por uma cor e tom escolhidos de forma pessoal e livre pelas participantes.

Compreendendo a vivência da coleta de dados como evento único enquanto experiência vivida, elaborou-se checklist da entrevista, para evitar interferências que pudessem invalidar a atividade, com as seguintes opções: TCLE assinado, aparelho de gravação (gravador e notebook) testado e posicionado, caneta, bloco para anotações e um diário de consolidação das entrevistas, que continha informações, como AC à qual a docente pertencia, sua cor, transcrição 
das entrevistas (dados brutos) e observações sobre a docente, percepções de sentimentos que chamaram a atenção no processo da entrevista. As anotações relativas às observações e percepções registradas no diário aconteceram ao término da entrevista, com o intuito de registrar todas as percepções e sentidos apreendidos do momento. O olhar atentivo, desprendido de "pré-conceitos" e falatórios é importante, para que seja possível compreender o fenômeno como ele se mostra.

Os relatos foram obtidos por meio da entrevista fenomenológica ${ }^{(7,14)}$, realizada pela pesquisadora principal, na qual solicitou-se às participantes que contassem sobre si mesmas e sua trajetória pessoal em relação à saúde mental. Essa estratégia foi utilizada para que a enfermeira-docente pudesse voltar às coisas mesmas, reviver a sua história e as experiências vividas em seu mundo e a sua relação com a saúde mental, antecipando, dessa forma, indícios de sua historicidade e temporalidade. Em seguida, foi utilizada a questão norteadora: Qual o sentido que você atribui à saúde mental e como ela emerge em seu cotidiano docente?

As entrevistas, realizadas no mês de setembro de 2017 e com duração média de 30 a 45 minutos, foram gravadas em áudio e vídeo e posteriormente transcritas, uma vez que o ente pode mostrar-se a si mesmo de várias maneiras, segundo sua via e modo de acesso ${ }^{(14)}$. As transcrições foram lidas atentamente, para familiarização e apreensão dos sentidos ali expressos.

O processo de sistematização e análise dos dados compreendeu o Círculo Hermenêutico. Este corresponde à interpretação ôntica e ontológica da fenomenologia em Heidegger, em que a interpretação do apreendido constitui-se nas possibilidades projetadas na compreensão ${ }^{(8)}$. Foram seguidos os três passos da fenomenologia ${ }^{(14-15)}$ : "pré-compreensão", compreensão e interpretação. Este último é inerente ao compreender e possui a possibilidade própria de se elaborar em formas. Interpretar é poder ser.
Por meio da análise compreensiva dos discursos e adoção dos conceitos da fenomenologia heideggeriana de historicidade, temporalidade, mundanidade, falatório e tradição, foi constituída a unidade de significado: compreende a saúde mental, na maioria das vezes de modo impróprio, como doença mental presente no falatório familiar, e apresenta conceitos e "pré-conceitos" estabelecidos no seu processo de formação, influenciados pelo modo de ser das docentes. Estas desvelaram as Unidades de Significação: Compreende a saúde mental, na maioria das vezes de modo impróprio, como doença mental presente no falatório do cotidiano familiar e nos processos de sua formação acadêmica; e Conceitos e "pré-conceitos" estabelecidos no processo de formação, influenciados pelo modo de ser das docentes.

O estudo foi aprovado pelo Comitê de Ética em Pesquisa, pelo Certificado de Apresentação para Apreciação Ética (CAAE) $\mathrm{n}^{\mathrm{p}}$ 09092612.2.0000.0018. As participantes foram identificadas por uma cor e tom escolhidos por elas de forma pessoal e livre.

\section{Resultados}

As oito participantes vivenciavam a experiência de ser enfermeiras-docentes nas ACs que antecediam a AC Enfermagem em Saúde Mental e Psiquiátrica, a saber: Exercício de Enfermagem (1), Introdução a Enfermagem (2), Atenção Integral a Saúde da Mulher, Criança e Adolescente (2), Atenção Integral à Saúde do Adulto e do Idoso (2), Práticas Educativas em Saúde (1). Tinham idade entre 30 e 54 anos e o tempo que estavam como docentes permanentes na Faculdade de Enfermagem variou entre 7 e 32 anos.

No encontro com as participantes, compreendeu-se que, em suas experiências vividas, evidenciadas nos discursos, elas enfrentaram problemas pessoais, familiares e profissionais de ordem mental, psicossocial, econômica e física sintetizados no Quadro 1. 
Quadro 1 - Historicidade das enfermeiras-docentes na relação familiar e sua vivência com a Saúde Mental

\begin{tabular}{|c|c|}
\hline Participante & Historicidade \\
\hline Rosa & $\begin{array}{l}\text { Filha de mãe solteira. Viveu dos } 4 \text { aos } 10 \text { anos em internato. Ficava com a mãe } \\
\text { no final de semana. A experiência acadêmica foi envolvida pelo medo do doente } \\
\text { mental, construído no processo de formação. A decisão de jamais querer trabalhar } \\
\text { com "aquilo" foi a lembrança da sua professora, dizendo-lhe que era franzina. }\end{array}$ \\
\hline Verde & $\begin{array}{l}\text { Pai negro e mãe branca. Dois irmãos "claros" e ela negra. Teve que superar } \\
\text { o preconceito social, racial e de gênero para vencer e sustentar a família. Pai } \\
\text { alcoolista, o que interferia na dinâmica familiar. No cotidiano do trabalho, diz que a } \\
\text { saúde mental na AB é apenas um repasse de medicamentos. }\end{array}$ \\
\hline Vermelho & $\begin{array}{l}\text { Sete irmãos. Pai alcoolista, mas não compreendia isso como um problema mental. } \\
\text { Mãe tentava manter a harmonia, evitando conflitos. Cresceu ouvindo que o "louco" } \\
\text { era perigoso. Tinha medo do professor de psiquiatria. Ele assustava. }\end{array}$ \\
\hline Azul Turquesa & $\begin{array}{l}\text { Quatro irmãos. Pais separados de forma brutal. Criação rígida na casa da avó. } \\
\text { Tem recordações sofridas da prática em psiquiatria e compreende o problema na } \\
\text { perspectiva da ótica religiosa. Desistiu de concurso público, para não trabalhar na } \\
\text { Psiquiatria. Diz não ter estrutura psicológica. }\end{array}$ \\
\hline $\begin{array}{l}\text { Vermelho } \\
\text { Sangue }\end{array}$ & $\begin{array}{l}\text { Filha única de mãe solteira. Não conheceu o pai. Dizia ser sistemática, } \\
\text { cartesiana e positivista. Tinha muito medo de doentes mentais, mas referiu } \\
\text { que sofreu várias perdas, apresentou quatro episódios de depressão e fazia } \\
\text { uso de medicação. }\end{array}$ \\
\hline Preto & $\begin{array}{l}\text { Saiu de casa aos } 17 \text { anos, à revelia, para estudar. Teve aversão à psiquiatria quando } \\
\text { amiga foi agredida por um paciente. Quase desistiu de um concurso, quando foi } \\
\text { designada para o Hospital de Custódia. }\end{array}$ \\
\hline Rosa Pink & $\begin{array}{l}\text { Mãe aos } 17 \text { anos. O fato mudou sua relação com a saúde mental. Odiava } \\
\text { as disciplinas Psicologia Aplicada à Enfermagem e Psiquiatria em Enfermagem } \\
\text { e acreditava que o acadêmico não tinha maturidade para compreender a } \\
\text { saúde mental. }\end{array}$ \\
\hline $\begin{array}{l}\text { Azul } \\
\text { Marinho }\end{array}$ & $\begin{array}{l}\text { Mimada pelos pais e irmãos. Nasceu com uma deficiência e submeteu-se a } \\
\text { várias cirurgias corretivas, fez acompanhamento psicológico, porque isso a } \\
\text { incomodava. Com as responsabilidades profissionais, sua vida pessoal ficou } \\
\text { relegada a segundo plano. }\end{array}$ \\
\hline
\end{tabular}

Fonte: Elaboração própria.

Considerando os conceitos de temporalidade, mundanidade, falatório e tradição complexos, que permeiam o ser do Ser-aí em toda sua singularidade e complexidade do viver, destaca-se que os achados deste estudo apontam para a compreensão da historicidade das docentes e dos modos de ser com os outros.

As duas unidades de significados que emergiram durante as entrevistas e que sustentam a interpretação ontológica da Unidade de Significação apresentada neste estudo revelam o sentido ôntico da compreensão das docentes em relação à saúde mental.

\section{Compreende a saúde mental, na maioria das vezes de modo impróprio, como doença mental presente no falatório do cotidiano familiar e nos processos de sua formação acadêmica}

O modo como as enfermeiras docentes referiram sua relação com a saúde mental em sua historicidade, na maioria das vezes, refletiu um modo inautêntico e impróprio, sem apropriação do conteúdo. Esta inautenticidade estava fortemente vinculada a sua relação com os outros no seu ser-com no cotidiano familiar e no falatório. 
Eu morava no interior e um morador de rua andava sujo, com um monte de livro e um saco. Todos diziam que ele havia ficado doido de tanto estudar. As crianças e eu tínhamos muito medo dele. As pessoas, inclusive meus pais, diziam que ele colocava a criança no saco. Tinha pavor de acontecer isso comigo. (Preto).

Não me lembro de conversar sobre saúde ou doença mental com a família, mas lembro de que a gente tinha muito medo do doente mental que vagava pelas ruas. Medo da aparência e da agressividade. Não sei de onde veio esse medo. (Vermelho sangue).

O meu pai virou alcoólatra. Perdeu a mãe jovem, fugiu de casa, viveu trabalho escravo, serviu a guerra e foi funcionário da marinha. Aprendi com mamãe, nunca discutir com alguém que bebe, pra não brigar. Ele não batia, mas se não bebesse seria melhor [Vermelho dá um pequeno sorriso emocionado]. (Vermelho).

Os dados apontam para o medo de se relacionar com pessoas que apresentam sofrimento mental. Essa condição parece distanciá-las da compreensão da transversalidade dos conteúdos da atenção à saúde mental. O medo era utilizado pelos pais das participantes como forma de controle do comportamento delas quando crianças. Muitas vezes, era suscitado pelo discurso de que quem pega é o "doido", que ele é mau. Essa questão, presente no falatório da família, refletiu-se nas falas de Preto, Verde e Azul Turquesa.

\begin{abstract}
Meus pais sabiam como nos controlar. A forma como a sociedade apresenta a saúde mental está ligada ao mau, a doenç. E isso ficou marcado em minha história. O desespero no bospital de custódia. Só lembrava daquele senhor, do saco, que vai pegar, que agride... Eu não dei conta. (Preto).
\end{abstract}

Eu tinha muito medo na infância. "Fulano bate, fulano joga pedra". "Fulano é doido de jogar pedra". Meus pais, para a gente não ir brincar na rua, falavam que o bomem do saco ia pegar. Ficávamos "santos" em casa. Na prática, tinham histórias de profissionais que apanbavam, pessoas amarradas. Eu ia forçada. (Verde).

Quando criança, eu tinha muito medo daquelas pessoas que ficavam na rua. Acreditava que elas iam me levare que todas tinham doença mental. Então, eu me comportava direitinho. (Azul Turquesa).

O medo de sofrer o preconceito por determinada condição e, consequentemente, a exclusão social colocava as participantes em condição de opressão, favorecendo que elas tomassem atitudes aceitáveis pela família e amigos, escondendo seus sentimentos, medos e reforçando os sentidos dados a atenção à saúde mental.

Eu tenho pânico de pegar um automóvel e sair dirigindo. Eu sou uma excelente aluna na teoria. Eu não sei se tenbo alguma divida, alguma leseira, algum problema. Nunca contei para ninguém, porque via como as pessoas, principalmente as da minha familia, quando tem uma situação parecida, fazerem gozação, falarem que a pessoa é lesa, ou que tem problema mental. Todo mundo me cobra. (Azul Turquesa).

Eu sou a única filha mulher e, infelizmente, eu fui a única a ter esse problema. Meus pais são primos legítimos e já falavam que um podia nascer com doença mental. Para minha mãe, que idealizava ter uma filha mulher, quando nasceu uma, nasceu com essa deformidade. Hoje eu entendo o que ela passou, mas foi muito complicado, não podia fazer nada. (Azul Marinho).

O desvelado aponta para a compreensão de que os sentidos foram construídos no ser-com do Ser-aí nas relações familiares e nas vivências infantis e adolescentes e consolidados na formação profissional e nas relações estabelecidas com suas docentes.

Conceitos e "pré-conceitos" estabelecidos no processo de formação influenciados pelo modo de ser das docentes

As enfermeiras-docentes relacionavam o fato de terem dificuldades em abordar conteúdos em relação à atenção à saúde mental no cotidiano da docência com as suas vivências acadêmicas. O conceito e "pré-conceito" constituem-se com base em questões presentes no falatório, que pode ser pessoal, institucional e relacional.

Os dados desvelam que, no processo de formação das participantes, a presença de suas docentes, seus posicionamentos e posturas frente às questões da saúde mental marcaram e parecem ter influenciado as suas vidas, consolidando os sentidos que fundavam os seus modos de ser e reforçavam o sentido dado à saúde mental como doença mental. O falatório na academia a respeito da saúde mental reproduziu o conceito de que a saúde mental estava ligada ao perigo. No cotidiano, na tradição, essa reprodução desencoraja a aproximação e o interesse pela temática, como expressam as falas de Rosa e Rosa Pink:

O medo marcou meu primeiro contato com a atenção à saúde mental na academia. O conteúdo era voltado para as doenças. Nossas práticas eram no bospital. A gente tinha muito medo de entrar lá e o professor que nos acompanhava dizia para ter cuidado. Nas aulas teóricas, os professores colocavam que a loucura gera uma força extrema e olhavam pra mim, dizendo que eu era muito franzina, que eu não servia para trabalbar, que eu era muito fraca, que eu ia ficar louca. Morria de medo de ser 
agredida. Decidi que eu não queria aquilo pra minha vida profissional. (Rosa).

Lembro que tinha medo do professor de psicologia. Ele parecia meio louco. A disciplina enfermagem psiquiátrica, também, nunca me chamou atenção. Não gostava do conteúdo. O paciente psiquiátrico é pegajoso, me dá medo e aversão. No estágio, um usuário de drogas agrediu uma assistente social. A agressividade marca a vida, e a gente se distancia. Hoje, com os alunos, evito ficar nas proximidades da ala psiquiátrica. Incomoda-me. (Rosa Pink).

A apreensão de significados também é refletida pela dimensão do tempo, porém outro elemento aparece para compor a existência temporal: o espaço. Tempo e espaço ocupam juntos a temporalidade das docentes. Nesse sentido, o hospital acolhe pessoas perigosas.

Quando nós fomos desenvolver a prática, não tivemos um preparo prévio do que nós iríamos encontrar. Uma das colegas foi agredida por um paciente, fiquei com aversão. Aquilo ficou marcado. Não queria trabalhar em psiquiatria. Os próprios professores nos afastavam, colocando medo da psiquiatria. Na hora da prática, eu me desesperava. (Preto).

O que eu tinha mais medo, quando me formei, era trabalbar na psiquiatria. As recordações da época de estudante são muito sofridas. Pela formação espírita, eu conseguia identificar, naquele local, alguns círculos, onde os espiritos estavam desarticulados, insatisfeitos com toda situação deles, eles acabavam influenciando no comportamento dos pacientes. Foram quinze dias de sofrimento. (Azul Turquesa).

As experiências de vida constituem um exercício de vir a ser, pois, dessa maneira, o questionar a realidade e buscar caminhos diferentes constituem o ser enfermeira-docente mais sensível para a transversalidade dos conteúdos da saúde mental.

\section{Discussão}

O sentido apreendido nos depoimentos das enfermeiras-docentes está fundado pela temporalidade e mundanidade dessas, enquanto ser de tradição. A reflexão sobre mundanidade torna possível compreender a historicidade como um caminho para a temporalidade do ser ${ }^{(16)}$ e constituir a possibilidade de ser autêntico. Contudo, o sentido enquanto reunião antecipadora que constitui a mundanidade do mundo e a existencialidade do Ser-aí das enfermeiras-docentes como cura, ainda não se constitui como uma possibilidade de incorporar, de forma própria, a atenção à saúde mental em suas ACs.

Por outro lado, a compreensão projeta a enfermeira-docente em possibilidades de existência, em que ela pode ou não assumir de modo pleno sua existência. Somente, então, dá-se a interpretação de mundo no discurso e na linguagem. Contudo, muitas vezes, a compreensão é possível sem nada dizer: o silêncio fala muito mais do que muitas palavras ${ }^{(7)}$. Por outro lado, o falatório é um dos fenômenos que encobrem o compreender e pode levar o Ser-aí a se perder no ambiente público e impessoal.

Nas falas das enfermeiras-docentes, compreende-se que elas vivem o dia a dia na decadência existencial ontológica do ser-aí fático, no qual o falatório, a ambiguidade e a curiosidade aparecem como momentos de não proximidade delas consigo mesmas enquanto enfermeiras-docentes na relação com a saúde mental. Sendo-no-mundo compartilhado e circundado por familiares, docentes - colegas de trabalho - e discentes, foi na ocupação e na manualidade dirigida aos e pelos instrumentos, sendo-com deficiente que elas experimentaram a docência dia a dia.

Por vezes, elas demonstraram angustiar-se, ao se depararem, na prática, com o sofrimento mental, o que se anunciou como ser de possibilidades, para logo em seguida decair, alienada e aprisionada no cotidiano. No cotidiano, sempre se dá respostas às demandas do mundo numa ocupação. Autores $^{(7,13,17)}$ corroboram essa afirmativa, ao expressarem que a ocupação refere-se ao trato com os entes simplesmente dados e participa do cuidado de ser, à medida que o trato com os entes no mundo abre possibilidades de relação com o mundo e, portanto, possibilidades de ser a cada momento desse ou daquele modo.

Nesse sentido, as enfermeiras-docentes podem acompanhar o que já vem acontecendo com enfermeiras na clínica que, ampliando sua visão de mundo, têm se movimentado na construção epistemológica que perpassa experiências, vivências e problemáticas advindas de seu cotidiano laboral, englobando temas 
voltados para a saúde mental, do trabalhador, do adulto, do idoso, da criança, do adolescente e da mulher, desvelando fenômenos em suas diversas facetas ${ }^{(18)}$.

O falatório é a possibilidade de tudo entender sem uma prévia apropriação da coisa ${ }^{(8)}$. Nesse sentido, o modo como as enfermeiras-docentes referem a sua relação com a saúde mental em sua historicidade, na maioria das vezes reflete um modo inautêntico e impróprio, sem apropriação do conteúdo. Esta inautenticidade está fortemente vinculada a sua relação com os outros no seu ser-com-cotidiano familiar. As participantes deste estudo, de maneira geral, compreendiam a saúde mental, de modo impróprio, como doença mental presente no falatório familiar.

A loucura caracteriza-se estritamente pela forma como a sociedade experimenta, vivencia essa relação com a loucura. Para alguns autores $^{(19)}$, ela é a herdeira da lepra. No falatório relativo aos dois casos, a exclusão foi adotada como resposta a um mal complexo demais para ser solucionado, mas foi necessário um longo período de latência, para que a loucura, assim como a lepra, desencadeasse reações de divisão, constituindo um espaço moral de exclusão.

A desconstrução desse paradigma demanda uma atitude solidária para a compreensão da complexidade da pessoa humana e de suas dores. As participantes confirmaram, quando apresentaram os conceitos de medo e necessidade de afastamento de quem sofre mentalmente presentes no falatório, que a desinstitucionalização, como processo ético que reconhece a complexidade da pessoa e sua relação com a vida, é o princípio da reforma psiquiátrica que ainda não foi consolidado.

Assim, a vivência de ver pessoas familiares rotularem alguém com dificuldade para desempenhar uma atividade, com dificuldades emocionais, econômicas e não físicas, como uma pessoa com transtorno mental, ajuda na construção do sentido de ser algo difícil, de ser algo ruim que deve ser afastado. Esse afastar-se distancia a docente da docência mais humanizada, mais integral e mais própria.

Quando as enfermeiras-docentes usam a palavra saúde para falar sobre a doença, indicam que a saúde mental não é compreendida em todas as suas dimensões - transversalidade, especificidade e especialidade. É na dimensão da especialidade que as pessoas, em sua maioria, compreendem a saúde mental. Logo, ela é compreendida como doença.

Desse modo, campanhas e ações educativas para reduzir o estigma das pessoas em sofrimento mental, incluindo orientação à população em relação às doenças mentais e o apoio à criação e ao fortalecimento de associações de familiares, de pessoas em sofrimento mental e comunidade, são necessárias para a construção de uma sociedade mais solidária e diminuição do estigma.

Conceitos e "pré-conceitos" estabelecidos no processo de formação das enfermeiras-docentes influenciados pelo modo de ser das suas docentes contribuíram de forma significativa para o modo como elas compreendiam e atuavam na docência, como aparece expresso nas falas. Para elas, o falatório durante a sua formação a respeito da saúde mental reproduzia o conceito de que a saúde mental estava ligada ao perigo. No cotidiano influenciado pela tradição, essa reprodução desencorajava a aproximação e o interesse pela temática.

Os modos de ser das docentes podem influenciar os modos de ser das futuras enfermeiras. Esse fato é importante e deve ser considerado, uma vez que, se as docentes distanciam-se do Ser-aí das acadêmicas de enfermagem, colocando-se nessa relação de maneira autoritária, estarão contribuindo negativamente na formação de uma profissional para um cuidado integral da pessoa.

Se o processo de formação não aproximar as enfermeiras-docentes do modo de ser do Ser-aí e não abri-lo para o ser da discente, esta não se pensará como ser-no-mundo e jamais será autêntica. Ao contrário, será sempre e somente inautêntica $^{(20)}$. O estar lançado na existência obriga o Ser-aí das enfermeiras-docentes a buscarem sentidos. Para essa tarefa, elas, enquanto educadoras e pensadoras, podem preparar o terreno e acompanhar as discentes naquilo que nunca deixa de inscrever. A preocupação com os outros, que qualifica as enfermeiras em seu cuidado 
no cotidiano, não estabelece o Ser-aí como privilegiado, pois não o retira da cotidianidade ${ }^{(20)}$.

Estudos $^{(5,15,21)}$ apontam que o cuidado com a formação é um modo de ser na presença com compromisso em relação a quem se ensina, fazendo escolhas e tomando decisões com responsabilidade. Ensinar é indicar, a quem deseja aprender, aquilo que já se tem. Daí que a tarefa premente das docentes das ACs que compreendem o conceito ampliado de saúde em sua dimensão biopsicossocial é oferecer a oportunidade e criar possibilidades de as discentes de enfermagem reconhecerem em si essa identidade autêntica fundamental e como essa se dá.

A temporalidade é revelada enquanto sentido desse ente denominado Ser-a ${ }^{(8)}$. Por isso, o tempo revela-se como a constatação do Ser-aí; é de onde ele parte e interpreta o ser-no-mundo. É inegável a dimensão do tempo na vida das participantes, pois ele condiciona a existência humana e consolida sentidos expressos em seus modos de ser. Contudo, presas ao cotidiano temporal, não relacionam vivências, como ser mãe adolescente, assumir os papéis de esposas, donas de casa de forma precipitada e as consequências advindas dessas responsabilidades inesperadas, com a dificuldade de lidar com as questões relacionadas a atenção à saúde mental no cotidiano da formação e do trabalho.

A apreensão de sentidos é refletida nas dimensões tempo e espaço, que ocupam, juntas, a temporalidade. O espaço acompanha o que se considera significado; por isso, o tempo somente não remete a significações ou apreensões existenciais. A experiência no hospital, a fala do docente, a agressividade e o cheiro constituíram os sentidos das enfermeiras docentes.

A docente assume papel fundamental na formação das novas enfermeiras, contribuindo para que elas possam compreender o mundo e a diversidade de forma mais amorosa, crítica, respeitosa e criativa. Por meio das práticas pedagógicas, as docentes podem influenciar significativamente a trajetória das acadêmicas, contribuindo para o cuidado integral. Estudo ${ }^{(15)}$ afirma que, consoante Heidegger, o bom docente está mais avançado que seus alunos somente naquilo que tem mais a aprender do que eles, isto é, no fazer aprender.

O aprender e o ensinar são compreendidos em um sentido essencial ${ }^{(21)}$ e corrobora a afirmação haideggeriana de que todo ensinar é reconduzir quem aprende ao "lugar" de todo aprender. Assim, o aprender/ensinar seria recordar essa instância na qual se constituem os significados capazes de orientar a existência desse indivíduo que aprende. As enfermeiras docentes, ao serem estimuladas a recordarem suas experiências e sensibilizadas para a questão da saúde mental como conteúdo transversal, poderão resignificar e dar novos sentidos aos seus modos de ser.

\section{Conclusão}

Os sentidos que fundam o modo de ser das enfermeiras-docentes em relação à saúde mental estão ligados à temporalidade, mundanidade e historicidade, subordinados tanto ao falatório do cotidiano familiar como aos processos de sua formação acadêmica. Tais sentidos emergem como algo simplesmente dado, refletindo diretamente no seu ser docente. Portanto, as docentes compreendem a saúde mental, na maioria das vezes de modo impróprio, como doença mental presente no falatório do cotidiano familiar e nos processos de sua formação acadêmica, além de apresentarem conceitos e "pré-conceitos" estabelecidos no processo de formação influenciados pelo modo de ser das docentes. A reflexão acerca da mundanidade tornou possível compreender a historicidade como um caminho para a temporalidade do ser. Desse modo, o ser enfermeira-docente possibilitará modificar o sentido dado à saúde mental no cotidiano da docência.

\section{Colaborações:}

1 - concepção, projeto, análise e interpretação dos dados: Aline Macedo de Queiroz, Josicélia Dumêt Fernandes e Larissa Chaves Pedreira;

2 - redação do artigo e revisão crítica relevante do conteúdo intelectual: Aline Macedo 
de Queiroz, Elizabeth Teixeira, Andrey Ferreira da Silva, Lília Pereira Lima e Rita do Socorro Ribeiro Quaresma Oliveira;

3 - aprovação final da versão a ser publicada: Josicélia Dumêt Fernandes e Larissa Chaves Pedreira.

\section{Referências}

1. World Health Organization. The World Health Report 2001. Mental Health: New Understanding, New Hope. Tradução portuguesa. Lisboa; 2002.

2. Brasil. Ministério da Saúde. Reforma Psiquiátrica e Política de Saúde Mental no Brasil. 15 anos depois de Caracas [Internet]. Brasília (DF); 2005 [cited 2018 Jan 15]. Available from: http://bvsms. saude.gov.br/bvs/publicacoes/Relatorio15_anos_ Caracas.pdf

3. Brasil. Ministério da Saúde. Portaria no 3.088, de 23 de dezembro de 2011. Institui a Rede de Atenção Psicossocial para pessoas com sofrimento ou transtorno mental e com necessidades decorrentes do uso de crack, álcool e outras drogas, no âmbito do Sistema Único de Saúde [Internet]. Brasília (DF); 011 [cited 2018 Jan 15]. Available from http://www.brasilsus.com.br/ legislacoes/gm/111276-3088.html

4. Oliveira WA, Silva JL, Scarpini NAM, Munõz SS, Silva MAI, Gonçalves MFC. Professor training in health postgraduate studies: analysis of an experience. Rev Bras Enferm. 2018;71(6):3115-20. DOI: http://dx.doi.org/10.1590/0034-7167-2017-0319

5. Sebold LF, Kempfer SS, Girondi JBR, Prado ML. Perception of nursing faculty on the care: Heidegger constructions. Rev Esc Enferm USP. 2016;50(n esp):39-46. DOI: http://dx.doi. org/10.1590/S0080-623420160000300006

6. Kurimoto TCS, Penna CMM, Nitkin DIRK. Knowledge and practice in mental health nursing care. Rev Bras Enferm. 2017;70(5):973-80. DOI: http://dx.doi.org/10.1590/0034-7167-2016-0343

7. Felix W. A ontologia mortal de Martin Heidegger. Nat hum [Internet]. 2017 [cited 2020;19(2):95-113. Available from: http:// pepsic.bvsalud.org/scielo.php?script $=$ sci arttext\&pid=S1517-24302017000200006\&lng=pt\&n $\mathrm{rm}=\mathrm{iso}$

8. Heidegger M. Ser e tempo. Tradução, organização, nota, prévia, anexo e notas Fausto Castilho.
Campinas (SP): UNICAMP; Petrópolis (RJ): Vozes; 2012.

9. Lima MM, Reibnitz KS, Kloh D, Silva KL, Ferraz F. The pedagogical relationship in practical-reflexive education: characteristic elements of teaching integrality in nurse education. Texto contexto-enferm. 2018;27(2): e1810016. DOI: http://dx.doi.org/10.1590/0104070720180001810016

10. Brasil. Ministério da Saúde. Secretaria de Atenção à Saúde. Saúde mental na atenção básica: o vínculo e o diálogo necessários [Internet]. Brasília (DF); 2007 [cited 2017 Oct 8]. Available from: http://portal.saude.gov.br/portal/arquivos/ pdf/diretrizes.pdf

11. Martins GCS, Peres MAA, Santos TCF, Queirós PJP, Paiva CF, Almeida Filho AJ. Teaching undergraduate nursing in mental health as allied to the consolidation of the Psychiatric Reform movement. Esc Anna Nery. 2018;22(4):e20180164. DOI: 10.1590/2177-9465ean-2018-0164

12. Rodrigues WO, Mourão LC, Almeida ACV, Oliveira GS. Os limites do ensino teórico-prático da saúde mental na formação do profissional de saúde. Rev port enferm saúde mental. 2016;(spe 4):107-14. DOI: http://dx.doi.org/10. 19131/rpesm.0149

13. Queiroz AM. Saúde mental no cotidiano da formação em enfermagem: o-modo-de-serdocente [dissertação]. Belém (PA): Universidade Federal do Pará; 2014.

14. Castañeda RFG, Menezes TMO, Vargas MGO. Characteristics of the phenomenological interview in nursing research. Rev Gaúcha Enferm. 2017;38(2):e67458. DOI: 10.1590/19831447.2017.02.67458

15. Sebold LF, Carraro TE. Modos de ser enfermeiro-professor-no-ensino-do-cuidadode-enfermagem: um olhar heideggeriano. Rev bras enferm. 2013;66(4):550-6. DOI: 10.1590/ S0034-71672013000400013

16. Castañeda RFG, Prado ML, Kempfer SS, Vargas MGO. Transcendence, historicity and temporality of being elderly: nursing reflection-using Heidegger. Rev Bras Enferm. 2017;70(4):891-5. DOI: http://dx.doi.org/10.1590/ 0034-7167-2016-0275

17. Braga TBM, Farinha MG. Heidegger: em busca de sentido para a existência humana. Rev 
Aline Macedo de Queiroz, Josicélia Dumêt Fernandes, Larissa Chaves Pedreira, Elizabeth Teixeira, Andrey Ferreira da Silva, Lília Pereira Lima, Rita do Socorro Ribeiro Quaresma Oliveira

Abordagem Gestáltica [Internet]. 2017 [cited 2018 Mar 13];23(1):65-73. Available from: http:// pepsic.bvsalud.org/scielo.php?script $=$ sci_ arttext\&pid $=$ S1809-68672017000100008\&lng=pt\&t $\operatorname{lng}=\mathrm{pt}$

18. Amorim TV, Souza ÍEO, Salimena AMO, Padoin SMM, Melo RCJ. Operationality of concepts in Heideggerian phenomenological investigation: epistemological reflection on Nursing. Rev Bras Enferm. 2019 [cited 2020 Apr 11];72(1):304-8. DOI: 10.1590/0034-7167-20170941

19. Providello GGD, Yasui S. A loucura em Foucault: arte e loucura, loucura e desrazão. História, Ciências, Saúde. 2013;20(4):1515-29. DOI: http:// dx.doi.org/10.1590/S0104-59702013000500005
20. Azeredo JL. Selbstsorge - cuidado de si e Fürsorge - preocupação a partir de Heidegger: análise ontológica em relação à educação. Rev Linguagem, Ensino Educ [Internet]. 2017 [cited 2020 Apr 11];1(1). Available from: http://periodicos.unesc. net/lendu/article/view/3222

21. Gama A, Lima W. O aprender e o ensinar a partir da obra Que é uma coisa? de Martin Heidegger. Educação (UFSM). 2019;44:1-23. DOI: https://doi. org/10.5902/1984644437922

Recebido: 22 de maio de 2020

Aprovado: 4 de julho de 2020

Publicado: 8 de outubro de 2020

A Revista Baiana de Enfermagem utiliza a Licença Creative Commons - Atribuição-NãoComercial 4.0 Internacional. https://creativecommons.org/licenses/by-nc/4.0/

Este artigo é de acesso aberto distribuído sob os termos da Licença Creative Commons (CC BY-NC). Esta licença permite que outros remixem, adaptem e criem a partir do seu trabalho para fins não comerciais. Embora os novos trabalhos tenham de lhe atribuir o devido crédito e não possam ser usados para fins comerciais, os usuários não têm de licenciar esses trabalhos derivados sob os mesmos termos. 